\title{
Entre la representación y la figuración. El cine de la Nouvelle Vague: una revisión histórica
}

\author{
Arnau Vilaró I MonCASí \\ Universitat Pompeu Fabra \\ arnau.vilaro@gmail.com
}

Recibido: 22 de diciembre de 2015

Aceptado: 23 de febrero de 2016

\begin{abstract}
Resumen
Cincuenta años después del nacimiento de la Nouvelle Vague, sus herencias recibidas en el cine contemporáneo son inevitables. Figuras y motivos visuales; relatos, temas, rostros o lugares comunes; recursos estéticos y de lenguaje. Los ecos se manifiestan de diversos modos, cada filiación implica una relación distinta y por tanto una aproximación dispar para su análisis. Y sin embargo, tanto la academia como la crítica de cine siguen pensando en la Nouvelle Vague como un conjunto, un universo, una corriente o una tendencia estética. Pero, ¿existe una estética nouvellevaguesca? Y, si es así, ¿por qué abordar de nuevo su revisión histórica? A partir de las tesis de Deleuze sobre la imagen-tiempo y de la aseveración de Serge Daney según la cual la Nouvelle Vague contribuyó al paso de un cine del ideal a un cine de la alteridad, el artículo siguiente da respuesta a estas preguntas partiendo de la convicción que los cineastas franceses no crearon un estilo, sino que asentaron un método. Este método consistiría en poner en crisis una relación propia de la narración para hallar una nueva relación en términos de montaje y puesta en escena. En particular, el artículo sostiene que la Nouvelle Vague aboga por esta aproximación haciendo del filme el espacio que permite pensar la visibilidad de la imagen y su figurabilidad a partir de la búsqueda y la pérdida del objeto de deseo en el relato, de lo que resulta una lógica de las imágenes a medio camino entre la representación y la figuración. Para abordar el análisis, el artículo propone una revisión de las primeras obras de François Truffaut, Jean-Luc Godard y Alain Resnais, y el cine de Philippe Garrel como representante de la primera generación francesa después de la Nouvelle Vague.
\end{abstract}

Palabras clave: deseo; visibilidad; representación; figuración; cine francés; Nouvelle Vague.

\section{Between representation and figuration. Nouvelle Vague's cinema: a history revision}

\begin{abstract}
50 years after the birth of the Nouvelle Vague, the inheritance that the contemporary cinema receives from it is inevitable. Figures and visual motifs; stories, themes, faces or common places; aesthetic and language devices. The echoes appear in various ways, each affiliation involves a different relationship and therefore a dissimilar approximation to its analysis. And yet, both the academy and the film critics maintain their will to think the Nouvelle Vague as a whole, a universe, a stream or an aesthetic trend. However, does a Nouvelle Vague's aesthetic exist? And if so: why and how to address their historical revision? Taking Deleuze's thesis on the time-image and Serge Daney's assertion according to which
\end{abstract}


the Nouvelle Vague contributed to the passage of the cinema of the ideal to the cinema of otherness, the following article places its protagonists filmmakers in front of the conviction that their cinema did not create a style, but it established a method. This method came through a particular gesture: when the filmmakers saw in cinema a movement of desire that fails to reach the desired object and the failure of which allows to think about the nature of the image. From this discussion emerges a logic of images halfway between representation and figuration. To address this, the article revisits the early works of François Truffaut, Jean-Luc Godard and Alain Resnais, and the cinema of Philippe Garrel as a representative of the first French generation after the Nouvelle Vague.

Keywords: desire; visibility; representation; figuration; French cinema; Nouvelle Vague.

\section{Referencia normalizada}

Vilaró I Moncasí, A. (2016). Entre la representación y la figuración. el cine de la Nouvelle Vague: una revisión histórica. Historia y Comunicación Social. Vol 21, número 1, páginas 221-239.

Sumario: 1. Introducción. 1.1. Una tendencia: la cuestión de la visibilidad y la búsqueda del Otro. 1.2. Metodología. 2. La separación: de lo inevitable a lo necesario. 2.1. Antoine Doinel: el deseo en el flujo y reflujo de la realidad y la imaginación. 2.2. Una caricia en Hiroshima. 2.3. El apartamento de Le Mépris. 3. Continuidad y separación después de la Nouvelle Vague. El caso de la cicatriz interior de Philippe Garrel. 4. Conclusiones. 5. Referencias bibliográficas.

\section{Introducción}

De Hiroshima mon amour (Alain Resnais, 1959) a H Story (Nobuhiro Suwa, 2001); de Le Mépris (Jean-Luc Godard, 1963) a Mulholland Drive (David Lynch, 2001); de Les Quatre cents coups (François Truffaut, 1959) a In the Mood for Love (Wong Kar-wai, 2000). En 2002 Jean-Marc Lalanne escribe que, cincuenta años después del nacimiento de la Nouvelle Vague, las herencias que recibe el cine contemporáneo resultan inevitables. Las mismas resonancias del movimiento francés aparecen en otros grandes autores del cine contemporáneo: Tsai Ming-liang (Visage, 2009), Hong Sang-soo (In Another Country, 2012), James Gray (Two Lovers, 2008), Abbas Kiarostami (Copie conforme, 2010), Noah Baumbach (Frances Ha, 2012), Matías Piñeiro (Viola, 2012), así como del cine de autor español más destacado de los últimos años: el de José Luis Guerín (En la ciudad de Sylvia, 2007), Marc Recha (Pau i el seu germà, 2001), Mar Coll (Tres dies amb la família, 2009) o Jonás Trueba (Los ilusos, 2013). Figuras y motivos visuales; relatos, temas, rostros o lugares comunes; recursos estéticos y de lenguaje. Cada filiación implica una relación diferente y por tanto una aproximación dispar para su análisis. Pues, ¿acaso hay una relación evidente entre el uso de la palabra en el cine de Eric Rohmer, de Marguerite Duras o de Jean Rouch; o entre lo fantástico en Jacques Rivette, Alain Resnais o Jacques Demy; o entre las decisiones de montaje y puesta en escena en Jean-Luc Godard y François Truffaut? ¿Qué fueron los cineastas de la Nouvelle Vague si no la reivindicación del autor y de su discurso, cada uno desde sí mismo? 
Numerosos estudios demuestran el deseo de concebir la Nouvelle Vague como un movimiento colectivo. Destacadas obras como (Gauthier, 2002), (Heredero y Monterde, 2002) o (Ponce, 2006) constatan este afán, buscando en la obra colectiva distintos puntos de vista para encarar mejor la complejidad del fenómeno; empero, lo que es indicador del interés y la exhaustividad del estudio de la Nouvelle Vague es la consagración de ciertos investigadores a ello: (Andrew, 1978, 1983, 1987), (Buache, 1987, 1990), (Collet, 1963, 1972, 1977), (Crisp, 1993), (Prédal, 1984, 1991, 1996), (Baecque, 1998), (Douchet, 1998), (Riambau, 1995, 2002), (Memba, 2003), (Frondon, 1995), (Magny, 1986, 1987, 1992, 1993) o (Marie, 1997, 1999, 2012). Los estudios constatan que, por un lado, una serie de principios de ruptura son indiscutibles: el manifiesto de Alexandre Astruc sobre la "caméra stylo" (1992: 324-328), y el panfleto de François Truffaut publicado en 1954, "Une certaine tendance du cinéma français"; la política de los autores surgida de cineastas como Alfred Hitchcock, Howard Hawks, Jean Renoir, Orson Welles o Fritz Lang; finalmente, la revista Cahiers $d u$ Cinéma como soporte editorial ${ }^{1}$ y las ideas de su fundador, André Bazin, recogidas en ¿Qué es el cine? (1959-1962). Por otro lado, la Nouvelle Vague culmina con los criterios estéticos propuestos por el neorrealismo italiano: entre ellos, la reivindicación de películas personales, escritas, dirigidas y autofinanciadas por el cineasta; la desaparición del storyboard para dar margen a la improvisación; el uso del sonido directo, luz natural y escenarios cotidianos, o la presencia de actores desconocidos o no profesionales, etc.

Pero, ¿qué es lo que ha creado una herencia de la Nouvelle Vague? ¿Son estos criterios mencionados los que configuran un universo estético particular? Pero, ¿existe una estética nouvellevaguesca? Y, si esto es cierto, ¿cómo abordar la revisión de este momento decisivo y tan explorado por la crítica y la academia? En su artículo, Lalanne lanza la hipótesis que determina una tendencia general y que es el motivo de nuestro estudio: "La Nouvelle Vague fue un modelo, no en su estilo, sino en su gesto, un método a apropiarse, un germen" (2002: 80-81).

\subsection{Una tendencia: la cuestión de la visibilidad y la búsqueda del Otro}

En 1965 Jean-Luc Godard declaraba cuál era el lugar común que ocupaba junto con Rivette, Rohmer y Truffaut: "Tenemos más cosas en común que diferencias, las diferencias de detalle son grandes, pero las diferencias profundas son pocas. [...] Tenemos en común el hecho que buscamos" (1998: 235-236). La búsqueda a la que alude Godard coincide con lo que expresa Jean-Paul Belmondo en Pierrot le fou (1965), cuando en boca de Élie Faure, constata que, como en Velázquez, ya no se trata de pintar las cosas definidas, sino lo que hay entre las cosas. Tras la presentación del mismo filme, Godard declara que aquello propio del narrador francés -refiriéndose a Flaubert y a Proust- es que, a diferencia del americano, no sabe narrar historias. Como la literatura francesa, los grandes filmes de la modernidad tenían que seguir otro modelo, y este fue el de permanecer en el malentendido. $\mathrm{O}$ en su desconocimiento, así como lo consideró Godard tras el estreno de Vivre sa vie (1962): "Prefiero buscar en lo que no conozco que hacer algo que ya conozco" (1998: 225). 
Cincuenta años después de la Nouvelle Vague, Alexandre Astruc explica a Aldo Tassone que la renovación de los cineastas franceses llegó por un cambio de mirada sobre las películas: "De entrada se dejó de considerar como esencial la noción de 'cualidad del tema' [...] para interesarse en la puesta en escena y considerarla como una mirada sobre los filmes, una mirada preocupada por lo esencial" (2003: 29). He aquí el método al que se refiere Lalanne: el esfuerzo de una búsqueda que ya no obedece solamente a la narración, sino que debe plantearse desde el montaje y la puesta en escena. En este sentido son ineludibles las constataciones que sobre la Nouvelle Vague hicieron Gilles Deleuze desde la filosofía y Serge Daney desde la crítica. Si el primero vio en el movimiento francés un giro en la lógica de las imágenes, el segundo vio en el mismo una tendencia que arranca en la búsqueda del Otro.

Con el cambio en la concepción del relato Gilles Deleuze definió el paso del cine clásico al cine moderno, o lo que es lo mismo, de la imagen-movimiento a la imagen-tiempo. En la imagen-tiempo impera una inquietud por lo visible, esto es, el cine no ofrece una realidad ya descifrada, sino que presta atención a una realidad a descifrar. Dicho de otro modo, si la imagen-movimiento, fundada en base a la lógica de la acción-reacción, requiere de otra imagen para generar sentido, la imagen-tiempo, en cambio, sólo dispone de la imagen que presenta y ésta no responde a una lectura predeterminada de antaño (Deleuze, 2004: 11-21). A partir del neorrealismo, el cine se inquieta por la materia que tiene delante suyo, deja de interesarse por la acción para explorar lo que la imagen muestra en sí misma y, en consecuencia, el trabajo del cineasta ya no pasa por la apropiación de las imágenes, sino por el dejar aparecer en el devenir del objeto filmado. En Persévérance (1991), Serge Daney explicó este fenómeno como el paso de un cine del ideal a un cine de la alteridad:

La Nouvelle Vague [...] asumió la carga de algo totalmente distinto: un hombre y una mujer, la guerra de los sexos y una eventual resolución de esa guerra. En eso se invirtió toda la energía artística y creadora, entre 1960 y 1980 . Había que cambiar el cine del ideal, es decir el cine masculino (solo los hombres tienen ideales), por un cine que dejara aparecer a las mujeres. [...] Para los cineastas de la Nouvelle Vague, las grandes conmociones fueron la aparición de Brigitte Bardot, la foto de Harriet Andersson o Mónica Vitti (estábamos lejos de Michèle Morgan), imágenes de mujeres que imponían otro modo de filmarlas. El cine se ocupó de eso durante quince o veinte años y fue lo que en esa época transformó el lenguaje (1998: 113-114).

La transformación del lenguaje a la que alude Daney viene fundada en una paradoja que las mismas palabras del crítico francés dejan entrever: la actriz admirada, musa o amada se convierte en significante, toma el lugar de una significancia compartida con el héroe o con el director que la mira; pero el rostro femenino sería recordado por quien lo filmó: Ingmar Bergman y Harriet Andersson, Michelangelo Antonioni y Monica Vitti o Roberto Rossellini y Ingrid Bergman. Para Daney, lo que planteaba el cine moderno y la Nouvelle Vague en particular, era una cuestión generada por ambas miradas, una cuestión de relación. En otro texto, Daney escribe: "No fue con Doinel o Léaud con quien me identifiqué en 1959, sino lo que los ligaba con Truffaut" (Daney, 1993: 14). 
$\mathrm{Si}$, de acuerdo con Godard, el ejercicio de la Nouvelle Vague consiste en pensar lo visible y por tanto en crear un gesto de búsqueda, éste se entiende por la voluntad de llegar al Otro, manteniendo su interés en una relación íntima entre el cineasta y el objeto de representación. Este ejercicio se traduce, como en diversas ocasiones se ha objetado en relación con el cine de posguerra -desde Roma città aperta (Rosse1lini, 1945) hasta L'eclisse (Antonioni, 1962)-, en un abandono de la narración; pero también en la ambición por pensar, desde la praxis del cine, un discurso teórico sobre las imágenes. En esto precisamente apostó la Nouvelle Vague en gran medida, dando continuidad, de este modo, al trabajo que los cineastas plantearon ya antes como críticos. A su vez, esto explica que Deleuze vea en la Nouvelle Vague la culminación de la imagen-tiempo: por llevar la videncia a su reflexión, dando hincapié a la autorreferencialidad, mostrando el mecanismo del proceso de creación como un elemento necesario para el desarrollo del relato, concibiendo por tanto el artificio como inseparable de la narración. Desde la evidencia de la construcción del cine de género, en À bout de souffle (Godard, 1960) o Une femme est une femme (Godard, 1961), hasta la autoconciencia de la figura del narrador en Que la bête meure (Chabrol, 1969) o Le Genou de Claire (Rohmer, 1970), o el rodaje del film como método para explicar la creación, en La Nuit américaine (1973), L'Amour fou (Rivette, 1969) o Passion (Godard, 1982). El relato autorreferencial implica la reinvención de la ficción, tendiendo a una mayor dimensión reflexiva, y con ello la Nouvelle Vague hace que las imágenes respondan a una nueva lógica y plantee un nuevo sistema, interrogando y problematizando las viejas tesis de la imagen-movimiento. Pero, si este es el principal cambio de la modernidad, ¿cuál es la relación que éste guarda con el principio de alteridad al que alude Daney?

A modo de hipótesis, lo que culminó el cine moderno fue que, al plantear la búsqueda del Otro como discusión de la naturaleza de la imagen cinematográfica, la Nouvelle Vague empezó a pensar la representación como una cuestión de cine. O lo que es lo mismo: empezó a comprender que la representación debía pensarse en términos de figuración. Y esto fue decisivo para la construcción de un modelo a seguir por el cine posterior.

\subsection{Metodología}

Según Roland Barthes, la representación se encarga de abrir la discusión de la obra con la realidad y la mímesis, de pensar la imagen en términos de moral, verosimilitud o verdad; plantea la obra, pues, pensando en la lectura que la obra establece con su referente. La figuración, en cambio, reside en el "modo de aparición del cuerpo erótico" en el texto; esto es, en la presencia del autor en el texto, la concepción del deseo a partir del personaje, o en concebir el texto en sí mismo como el cuerpo de un lugar erótico. Cuando la representación toma por objeto de imitación el deseo mismo, este deseo "no sale nunca del cuadro, del libro, de la pantalla", sino que "circula entre los personajes" y "el destinatario reside interior a la ficción" (Barthes, 1974: 88-90). En la figuración, por lo tanto, reside el vínculo íntimo que une al cineasta con la imagen, el deseo de filmar y la búsqueda en la imagen. 
La atención de Jean-Luc Godard a la mirada de su amante y actriz Anna Karina en Une femme est une femme (1961), Vivre sa vie (1962) o Pierrot le fou (1965); o la búsqueda del objeto de deseo a partir de la construcción de un álter ego, como en François Truffaut y Jean-Pierre Léaud. Ambos cineastas evidencian que es a partir del estrecho vínculo con el Otro que la representación toma forma. Pero la relación con el Otro parece ser también el motor de los relatos de sus compañeros: el pensamiento de los héroes de "Cuentos morales" (1963-1972), o la búsqueda de las heroínas de "Comedias y proverbios" (1980-1987) son el testimonio mismo de la relación de Eric Rohmer consigo mismo y con el mundo; mientras que Jacques Rivette explora la misma relación desde la figura del metteur en scène que, desde Paris nous appartient (1960) y L'Amour fou (1969) hasta Va savoir (2001), planteando el cine como el terreno de un pensamiento dialéctico entre el mundo real y lo fantástico.

$\mathrm{Si}$, como hemos apuntado, la Nouvelle Vague empezó a hacer cine para ver, lo hizo no sólo poniendo al Otro en el centro de su motivación creadora, sino desde la relación, y en concreto, poniendo en crisis la relación narrativa para mantener la relación -o más bien su búsqueda- desde la figuración, esto es, en términos de montaje y de puesta en escena. ¿Cómo transformar la pérdida del Otro dentro del relato en la búsqueda de la naturaleza de la imagen? He aquí la pregunta que, en nuestra opinión, se formulan estos cineastas.

Para dar respuesta a esta pregunta, las siguientes páginas proponen el análisis de los filmes mencionados por Lalanne, considerados hoy en día los filmes más representativos del inicio de la gran ola francesa: Les Quatre cents coups, Hiroshima mon amour y Le Mépris. En concreto, nuestro análisis tomará como punto de partida el tratamiento de la separación en la pareja como catalizador de algo irreparable, inevitable o ineludible para el devenir de la narración, pues en los tres filmes la separación abre el relato a la nueva lógica en el uso de las imágenes. A partir de Philippe Garrel, como representante del cine francés inmediatamente posterior a la Nouvelle Vague, la segunda parte del artículo plantea la continuidad del método inaugurado por los cineastas nacidos con la política de los autores, Bazin y Cahiers du Cinéma.

\section{La separación: de lo inevitable a lo necesario}

\subsection{Antoine Doniel: el deseo en el flujo y reflujo de la realidad y la imaginación}

Al final de Les Quatre cents coups (1959) François Truffaut homenajea el suicidio de Edmond en Germania anno zero (1948), uno de los momentos más emblemáticos del neorrealismo italiano. Sin embargo, sobre el pequeño Antoine Doinel (Jean-Pierre Léaud), la muerte se revela también como una salvación: cuando el actor mira atrás, allí le espera la mirada del director. Con la mirada a cámara de su héroe Truffaut congela la imagen y somete el personaje a la ausencia de tiempo. El mismo gesto que provocaba la ruptura llevaba a la apropiación, al apadrinamiento de un niño nacido 
en un mundo hostil. Truffaut debería enseñar a su héroe el mundo que en su infancia no pudo ver, he aquí las aventuras de Antoine Doinel que Truffaut realizó entre 1962 y 1979.

En L'Amour à vingt ans (1962) Doinel abre las ventanas de su nuevo hábitat, escuchamos en el off: "Antoine realiza su sueño: vive solo, trabaja y no depende ya de nadie más que de sí mismo". A partir de este momento, Doinel viaja por un continuum de acciones dispares en el espacio y el tiempo. Truffaut convierte París en la ciudad que Baudelaire definió como el paisaje que ligaba el cuerpo a su ociosidad, o Cortázar como un laberinto inexplorable desde su forma pragmática. Un collage donde Antoine no tiene residencia fija ni estabilidad laboral y se entrega, desde la postura del flâneur, a la búsqueda de sensaciones en todos sitios y momentos. Truffaut lleva su personaje a una forma de sentir similar a la forma alienada con la que Jean-Jacques Rousseau describía su estado en Les Rêveries d'un promeneur solitaire: "Sobre la tierra todo es flujo continuo; nada guarda una forma constante y firme y nuestras afecciones, que se ligan a las cosas exteriores, pasan y cambian necesariamente como ellas" (1996: 102).

Confusión en el espacio, en el tiempo, pero también en la naturaleza de las "imágenes": es en la discusión entre la realidad y la imaginación que Doinel configura su deseo. Dicha realización proviene de la aproximación a la amada como un rostro creado desde las luces del cinematógrafo. Desde el seguimiento y el voyeurismo de los niños de Les Mistons (1957), que desean aproximarse a la muchacha que va en bicicleta (Bernadette Laffont, que poco después se convertiría en una de las musas de la Nouvelle Vague), esta misma mirada sigue existiendo en el último filme de Truffaut, Vivement dimanche! (1983), en la habitación oscura desde donde Jean-Luis Trintignant mira, como el espectador en la sala de cine, el caminar de las muchachas que pasean por la calle. La atracción por una nuca (Les deux anglaises et le continent, 1971), por unas piernas, unos zapatos de tacón o la actitud del cuerpo femenino en el mismo andar (La peau douce [1964], L’homme qui aimaît les femmes [1977], Vivement dimanche!), no son imágenes de un fetiche solamente, sino imágenes construidas desde la fabulación, que preservan el encantamiento, la distancia del romántico y el fugitivo de la literatura del XIX, que goza viendo y que no llega nunca a tocar.

"Jean-Pierre me interesa justamente por su anacronismo y su romanticismo: es un joven del siglo XIX” (Truffaut, 1999: 27-28). La misma visión determina la forma errante de Doinel, confundiendo no sólo el pasado y el presente, sino también la realidad y la ilusión. Truffaut expresa de este modo la noción de flujo con la que Bazin concibió el cine: "La pantalla reproduce el flujo y el reflujo de nuestra imaginación que se alimenta de la realidad, sustituyéndola; la fábula nace de la experiencia que la imaginación trasciende. Pero recíprocamente, hace falta que lo imaginario tenga sobre la pantalla la realidad espacial de lo real" (2008: 74). Truffaut escribió que la mejor película sería probablemente aquella que expresara a su vez ideas sobre la vida y sobre el cine. El último filme de la serie de Doinel, L'Amour en fuite (1979), culmina este proyecto: desde la acumulación de la experiencia, de las imágenes de los filmes anteriores, la separación de la realidad y el imaginario se hace ininteligible. 
Toda la fuente de confusión reside en la capacidad narrativa del héroe: las historias de amor de aires trovadorescos con las que Doinel concibe el deseo de Christine o Fabienne, o los monolíticos discursos creados al interior de las cabinas telefónicas, las palabras fabuladas por Doinel chocan siempre con la experiencia y la observación de la realidad. La autobiografía que Doinel escribe en L'Amour en fuite es testimonio de los dos universos de los que se nutre Doinel. En el relato de su vida tergiversa la verdad de los hechos para adaptarla a su gusto, a lo que recuerda o quiere recordar, a lo que le permite generar una nueva experiencia. Colette le retrae la falsedad de sus historias, pero admite la capacidad imaginativa de Antoine: "Tengo la impresión que seríais un gran novelista si llegaseis a construir una historia inventada por completo a partir de la imaginación". Antoine le explica entonces una historia imaginada: la de la fotografía de Sabine, encontrada hecha añicos en una cabina telefónica. El relato fascina a Colette, pero cuando Antoine abandona el compartimento del tren, la fotografía de Sabine inventada a priori cae al suelo revelándose por tanto real. La palabra -la de la escritura, de las cartas, de las llamadas- vira el rumbo de lo real e inversamente las imágenes de lo real contribuyen a cambiar el valor imaginario de la palabra. Fiel a las notas de Bazin, Truffaut materializa la afirmación que según JeanLuc Nancy forma parte de la esencia cinematográfica cuando anuncia que "el cine [...] da lugar a una lucha entre una presencia textual (el sentido comprendido) y una ausencia imaginada (el sentido escondido al fondo de la imagen). Sólo la lucha entre los dos, según el ritmo del espectáculo, constituye propiamente la verdad de la cosa: la verdad del sentido", mostrando en conjunción la ausencia y lo visible, pero siendo consciente que se trata de dos espacios separados.
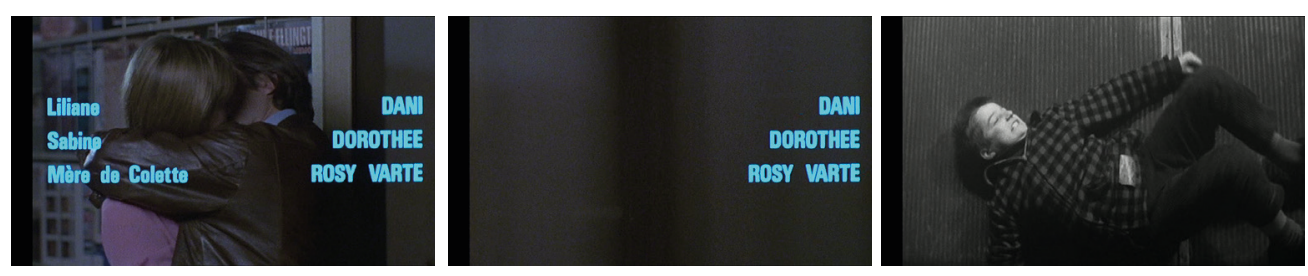

Fig. 1. A/B/C. L'Amour en fuite (François Truffaut, 1979)

En la última secuencia de L'Amour en fuite Truffaut confirma que según él, el trabajo del cine consiste en urdir distintos universos que, sin embargo, estarán siempre, en el cine, ontológicamente separados. Para decir adiós a su personaje, Truffaut invoca por última vez el primer Antoine Doinel de Les Quatre cents coups, y en concreto la secuencia en la que el héroe ocupa la atracción de feria. Para crear una relación entre el presente y esta imagen-recuerdo Truffaut invoca también la noción del "montaje prohibido" de Bazin (2008: 77) y simula una panorámica entre la imagen en presente de Antoine y Sabine besándose (fig. 1A) y la imagen del niño (fig. 1C). La imagen del niño emerge del espacio que ocupan dos desconocidos que, como Antoine y Sabine, también se besan en una cabina. Truffaut alude a la mímesis de las posturas y las palabras de amor, a la pérdida de la fuente original, del referente, a la diferencia y la relación entre lo que es y lo que se muestra o a la perseverancia para reunir en un mismo 
cuadro dos representaciones dispares. En suma, queriendo mostrar los distintos espacios, el ojo de Truffaut, el ojo que encarna el paseo de Antoine Doinel, se pierde en el vaivén, y el flujo y reflujo se convierte en inidentificable (fig. 1B) mostrando, de un modo similar a la naturaleza del flujo definida por Kracauer, "complejos visuales fragmentarios que se anulan entre sí, impidiendo así que el espectador se deje llevar por cualquiera de sus innumerables sugerencias" (1989: 103).

\subsection{Una caricia en Hiroshima}

Resnais convirtió la caricia que abre Hiroshima mon amour en un poderoso gesto capaz de evocar la memoria y de recuperar las imágenes perdidas después de la Segunda Guerra Mundial. Resnais muestra la voluptuosidad de los amantes como la imagen que sobrevive al dolor de la Historia y que permite recomenzar. La caricia de Ella, la francesa (Emmanuelle Riva), abre la puerta al recuerdo. La heroína comparte con Él, el japonés (Eiji Okada), la vivencia de un amour fou pasado que ella vivió en Nevers, en el pueblo donde nació. "Te encuentro, me acuerdo de ti". El recuerdo del pasado se convierte en una prueba de amor para el japonés y la caricia funciona como raccord: abre la posibilidad de recordar, de retener, de volver a ver el pasado y recuperarlo en el presente. Marcel Oms ya escribió sobre ello: "Podríamos decir muchas cosas sobre el rol de tocar en la recuperación del recuerdo; pues las manos y los dedos guardan físicamente la huella del pasado acariciado, abrazado, del contacto" (Oms, 1988: 78-79).

El gesto no supone sólo la posibilidad de revivir un amor. La caricia recorre entre la duda y la búsqueda de lo que ha sido visto o nunca fue visto: "No viste nada en Hiroshima", le dice él; "Sí, lo vi todo en Hiroshima", insiste ella. La caricia sigue el rastro que en sus primeros trabajos Resnais trazó desde un travelling. En Nuit et Brouillard (1956), el movimiento de cámara que cruza los campos de concentración filmados años después del holocausto tenía que dar visibilidad a la acumulación a los seis millones de cadáveres que descansaban bajo la hierba. Resnais convertía un travelling en una imagen compleja, de relación significante, como lo hizo Eisenstein a partir del montaje de atracciones o Welles con la profundidad de campo y el plano secuencia. Resnais entendió que el cine tenía que ambicionar un saber, sabiendo sin embargo que en él reside un no-saber por todo lo que excluye. Como las imágenes de Auschwitz, los libros de la Bibliothèque Nationale no lo recogen todo (Toute la mémoire du monde, 1956), pero el recuerdo no muere hasta que el observador, pese a desconocer el objeto que mira, pese a no verlo nunca, deje de mirar (Les statues meurent aussi, 1953). El cine de Resnais, nacido con el Nouveau Roman, con Marguerite Duras, Alain Robbe-Grillet y Jean Cayrol, arranca con la insistencia de una mirada que no quiere dejar de ver un conocimiento inalcanzable, una mirada consciente de la aporía del tiempo. "El tiempo de saber, esto no existe", escuchamos en Hiroshima mon amour. 

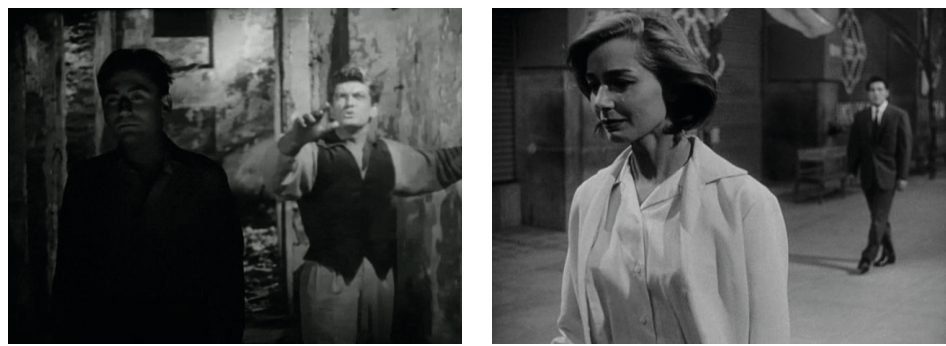

Fig. 2. A. L'Orphée (Cocteau, 1950) / B. Hiroshima mon amour (Resnais, 1959)

En el mismo filme visitamos el pasaje del espejo que Jean Cocteau en L'Orphée (1950) mostraba en un movimiento inverso, en ralentí, y superponiendo el recorrido del protagonista y el de la puerta del Hades (fig. 2A). Los amantes de Hiroshima también avanzan lentamente sin verse, adentrándose en el mismo descenso a los infiernos, pero Resnais prescinde de manipular el espacio y el tiempo y muestra que el mismo espacio puede ser otro y que en un tiempo conviven velocidades dispares. Él le pide a Ella que permanezca a Hiroshima mientras que Ella sigue adelante, dirigiéndose al avenir, pero hacia la izquierda del cuadro (fig. 2B), allá donde está su pasado, deseando ser cogida por el mismo pasado del que quiere escapar. Huir del pasado sería olvidar y por lo tanto la pérdida no sólo del otro, sino también de uno mismo; por ello, como bien vio Deleuze, la continuidad del travelling de Resnais está hecho de infinitas rupturas. Las últimas imágenes de Hiroshima mon amour llevan al espectador a este fenómeno, sobre todo cuando la cámara no deja de avanzar por el presente de Hiroshima, mientras visitamos distintos espacios (el pasado de Nevers, el futuro de París), cambios de punto de vista (Ella, Él) y de sonido (la voz dividida entre el off y el in, marcando los dos tiempos). El movimiento de cámara se convierte en responsable de hacer del tiempo el receptáculo y la inevitable pérdida, pero también el medio de relación y separación entre el objeto y su destino.

\subsection{El apartamento de Le Mépris}

En Le Mépris Jean-Luc Godard quiso explicar el final de su relación con Anna Karina, y para ello buscó un escenario cerrado (un apartamento) donde los cuerpos de Paul (Michel Piccoli) y Camille (Brigitte Bardot), separados, hallaran las posturas para sobrevivir a su pérdida. ¿Qué hacen, cómo se mueven, de qué hablan, y en definitiva, qué son dos cuerpos que ocupan un mismo espacio, estando definitivamente separados?

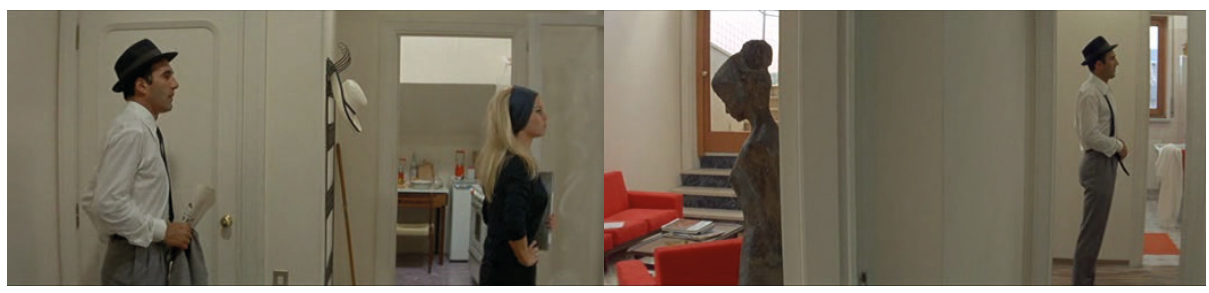

Fig. 3. A/B. Le Mépris (Jean-Luc Godard, 1962) 
El dilatado plano con el que empieza la secuencia del apartamento, de casi dos minutos de duración, arranca con una mirada de Camille fuera de campo (fig. 3A) y concluye con la misma mirada de Paul, también fuera de campo (fig. 3B). Plano dilatado en el tiempo, pero también en el espacio: Camille y Paul buscan al otro allí donde no hay nadie, mientras la continuidad temporal y la visión panorámica del Cinemascope se esfuerza en unirlos. En la puesta en escena que prepara Godard entre Paul y Camille, ninguno de los dos puede ver al otro. El tiempo y la longitud del cuadro magnifican el obstáculo a superar, los muros blancos por los que transitan los amantes expresan el hiato que los separa. La profundidad de campo, que permite el conocimiento del espacio donde se desarrolla la acción, evidencia una relación que ya no existe: por un lado, como en el cine de Antonioni, los cuerpos quedan relegados al margen y el intervalo ocupa el centro de la imagen; por otro lado, los amantes necesitan gritar para poderse comunicar, pero Le Mépris no muestra la incomunicación tras la fatiga de los cuerpos, sino la incomunicación que se impone frente a un cuerpo que se resiste a la fatiga. Somos espectadores de una gran imagen de desequilibrio a partir de dos cuerpos que buscan la supervivencia al centro del cuadro. Según Alain Bergala, en el apartamento se trataba de ver este desfase:

El tema de El desprecio no es más que eso: mirar lo que ha ocurrido en una pareja no durante años (como en el cine de los guionistas), sino durante una décima de segundo, precisamente esa en la que se ha producido el desfase, en la que por primera vez se ha instalado la confusión. Esa décima de segundo, invisible al ojo desnudo, en la que las velocidades ha dejado de estar sincronizadas. De nuevo es una cuestión de montaje: volver al corte para encontrar el raccord o el desajuste. [...] Godard utiliza los medios del cine -como otros los del microscopio electrónico o del bisturí con láser- para ver algo que de otro modo escaparía a nuestra escala de percepción ordinaria: cómo se puede pasar en una fracción de segundo, entre dos planos, de la confusión al desprecio, de una desincronización imperceptible a un vuelco de los sentimientos (2003: 29-30).

Cuando la duda invade los sentimientos ya no tiene sentido pedir la complicidad que habría existido antaño, cuando "todo se cumplía con una inadvertencia rápida, loca, encantada; me reencontraba en los brazos de Paul, sin recordarme a penas qué era lo que había pasado". Camille procura que el desfase del sentimiento sea reparado por el mismo sentimiento; Paul, en cambio, quiere conocer la verdad, buscar el motivo, situarlo en su momento, porque desde la razón el problema pueda solucionarse. En Pierrot le fou Godard situará a la pareja (Jean-Paul Belmondo y Anna Karina) frente al mismo problema: si él habla con palabras, ella lo hace con sentimientos.

En la ruptura y recuperación al apartamento de Le Mépris asistimos a las imágenes más bellas sobre las palabras -entonces todavía inocentes- con las que Godard vislumbraba el avenir del cine en "Montage mon beau souci" ["Montaje, mi hermosa inquietud"] (1956): cuando la mirada de la puesta en escena y el latido del corazón del montaje se confunden, lo que permite que la impresión de continuidad emerja pese al corte, pese a la separación, pese al olvido, o al sentimiento de melancolía que domina en Histoire(s) du cinéma (1988-1998). "El montaje, en consecuencia, al mismo tiempo que la niega, anuncia y prepara la puesta en escena", leemos al final del texto 
del joven Godard (2005: 35). El montaje debería ser no sólo la inquietud (souci) de la relación entre el pensamiento y la realidad, sino el espacio del pensamiento mismo del cine y la formación de una nueva gestualidad. En Amnésies Jacques Aumont toma estas tres ideas a partir de una aproximación kantiana a Histoire(s) du cinéma. La tercera es la que aquí nos interesa: encontrar el gesto de la ocasión fulgurante que convive con la presencia del montador (Aumont, 1999: 13-25). El gesto que permite que la invención más propia del cine, la herramienta de su especificidad, pese a la impotencia de la ruptura con la continuidad, pueda abrirse a nuevas posibilidades de continuidad. El gesto que permite reparar el desfase, el décalage entre los amantes, que a su vez se impone porque el rostro no se transforme en imagen-movimiento sometido al relato, a la transmisión de una continuidad, sino que pueda mostrarse él mismo en el tiempo.

Resnais y Godard se encuentran con Rohmer y Rivette: desde la pasividad y la entrega del cuerpo al tiempo, las heroínas de Rohmer, especialmente a partir de Le rayon vert (1986), crean su relato. $\mathrm{Y}$ es el tiempo y no la respuesta inmediata de la imagen quien determina la visualidad del cuadro de La Belle noiseuse (1991). La mirada dubitativa sobre las imágenes llevaba a los cineastas de la Nouvelle Vague a erigir discursos dialécticos en términos de cine: hacer de un travelling el espacio de un presente y un pasado (Resnais); situar el campo y el fuera de campo en el mismo espacio de la espera (Rohmer); hacer del cuadro el espacio de una resistencia (Godard); romper los muros de la escena para situar el teatro en la misma realidad (Rivette), o convertir al actor en receptáculo de la mediación entre la realidad y la imaginación (Truffaut).

\section{Continuidad y separación después de la Nouvelle Vague. El caso de la cicatriz interior de Philippe Garrel}

Los filmes posteriores a la Nouvelle Vague convertirían la separación en una necesidad ya no para ver, sino para existir. Jean Eustache, Philippe Garrel, Leos Carax, Maurice Pialat, Chantal Akerman o Jacques Doillon. Nacidos con el espíritu de la Francia del 68, sus relatos, los cuerpos que en ellos habitan, debían reivindicar su existencia en y desde el mismo dispositivo. No se trataría ya de abogar por formas de deconstrucción del cine institucional, tampoco por plantear la esencia del filme desde la consciencia de la realidad, sino por buscar las figuras que la separación pide. Los rostros se enfrentan a su deshecho, rechazados o faltados de relación, de mirada. A diferencia de los filmes de la Nouvelle Vague, donde el diálogo con el otro era todavía posible, en el cine que proseguía el otro ocuparía el espacio ausente. Por consiguiente, sólo queda un rostro lleno de lágrimas, de llantos que se resisten, como un canto al amor antes de morir. Imágenes del ahogo, de la asfixia, del sollozo. Françoise Lebrun en La Maman et la putain (Eustache, 1973), Jean en Nous ne vieillirons pas ensemble (Pialat, 1972); La femme qui pleure (1979), de Jacques Doillon, o Chantal Akerman en la habitación de Je tu il elle (1974). Las heridas se abren por 
doquier, sólo su apertura parece dar visibilidad al sufrimiento, mientras ambicionan huir al cierre, o permanecer en el cierre para afirmarse como posturas de repetición y de circularidad. ¿Cómo dar voz a un cuerpo que se afirma desde el margen? ¿Cómo hacerlo partícipe de la imagen cuando ocupa el corte que separa los planos?

En este movimiento reside el cine de Philippe Garrel, reconociendo en la separación el método necesario para hacer cine. "Al origen de mis películas hay siempre un conflicto, algo doloroso, y la separación, para mí, es la escena primitiva" (Garrel, Lescure, 1992: 22). Separación que supone una ruptura con la sociedad (Les enfants desaccordés, 1964), con el padre (Anémone, 1968), con el hijo (Le révélateur, 1968), con la Tierra (Le lit de la vierge, 1971). Fabrice Revault d'Allones escribió que la separación resume en una palabra el tema de Garrel y que "formalmente, el plano garreliano luchará contra esta desaparición de los seres queridos, a tentar de retenerlos, de mirarlos ${ }^{2}$ el máximo tiempo posible y, fatalmente, registrar el carácter inexorable, irremediable, de su desaparición" (Païni, 1988: 29).

Si Gilles Deleuze concibió el cine de Garrel como el fundador de un cine de cuerpos fue precisamente porque planteó el cuerpo desde su ausencia. El relato garreliano no pide hacer del cuerpo el elemento partícipe de un espacio, pues esto sería someter el cuerpo a un comportamiento ajeno a sí mismo. Para ser de cine, el cuerpo debía nacer desde una postura de cine: visto y asumido, observado y absorbido desde la cámara, de acuerdo con una nueva manera de montaje, haciendo que la condición de existencia del cuerpo dependiera estrictamente del ejercicio generado en el sí del plano y del montaje en particular. Crear el cuerpo a partir de "gestus" y no sólo de actitudes de cuerpo (Deleuze, 2004: 255). Lo que importa en el cine de Garrel, como lo apunta Deleuze a partir de Jean-Louis Schefer en L'homme ordinaire du cinéma, no es la "presencia", que es patrimonio del teatro, sino la génesis de un "cuerpo desconocido", concretamente un "comienzo de visible que no es todavía figura, que no es todavía una acción". El cine debe ser capaz de volver a dar el mundo y el cuerpo a partir de su ausencia y para ello "es preciso que la cámara invente los movimientos o posiciones que corresponden a la génesis de los cuerpos y que sean el encadenamiento formal de sus posturas primordiales" (Deleuze, 2004: 267, 265-268). El plano conjunto y el travelling en La cicatrice intérieure, el montaje en paralelo en Un ange passe (1975), la imagen inmóvil y silenciosa en Athanor (1972) y Le bleu des origines (1979), o la elipsis en Liberté, la Nuit (1983): tal como lo estudia Nicole Brenez, nos encontramos frente a nuevos encadenamientos, nuevas posturas de cine, esto es, nuevas formas de montaje desde la presencia de los cuerpos (Brenez, 1998: 65-75; Casas, 2007: 73-79).

Fue la experiencia de l'amour fou que Garrel vivió junto a Nico, la cantante alemana de Velvet Underground y modelo de la Factory de Andy Warhol, quien llevó a esta exploración. Garrel arranca en un cine estrictamente experimental, donde Nico se convierte en su mundo a filmar, en la posibilidad del goce desde el tormento. Como Garrel, Nico era víctima de la misma distancia respecto al mundo, del mismo sufrimiento, ella también creyó en el arte como el lugar de una salvación, y este mismo sentimiento de guerra los unía: "No entendía siempre lo que ella decía, pero 
teníamos en mente lo mismo, que éramos hijos de dos países que habían estado en guerra" (Garrel, Lescure, 1988: 86). Nico escribió los diálogos de La cicatrice intérieure (1972) en alemán, Garrel no entendía el idioma, pero confiaba en ella, pues compartían el mismo sentimiento: "La dejaba hacer. Sabía que pensaba el mundo exactamente como yo lo pensaba" (Courant, 1983: 60). Lo decisivo fue vivir la experiencia con el otro, junto al otro: "La única intención era expresar el amor que tenía por ella. O más bien, el filme es el resultado de este amor. Es más, no soy propiamente el autor de los filmes de la trilogía, que fue verdaderamente realizada por Nico y por mí, ‘dialogada' por ella, firmada por los dos” (Garrel, Lescure, 1988: 64).

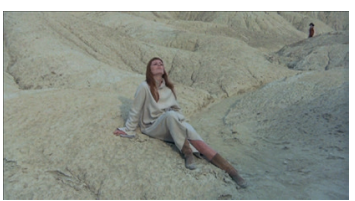

A
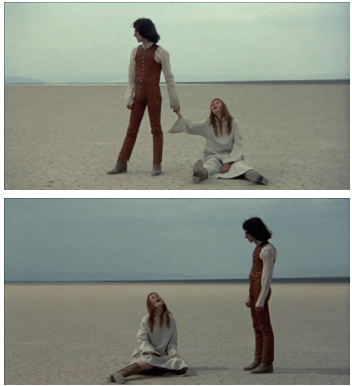

$\mathrm{B}$

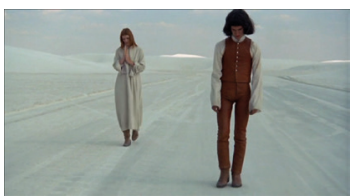

$\mathrm{C}$
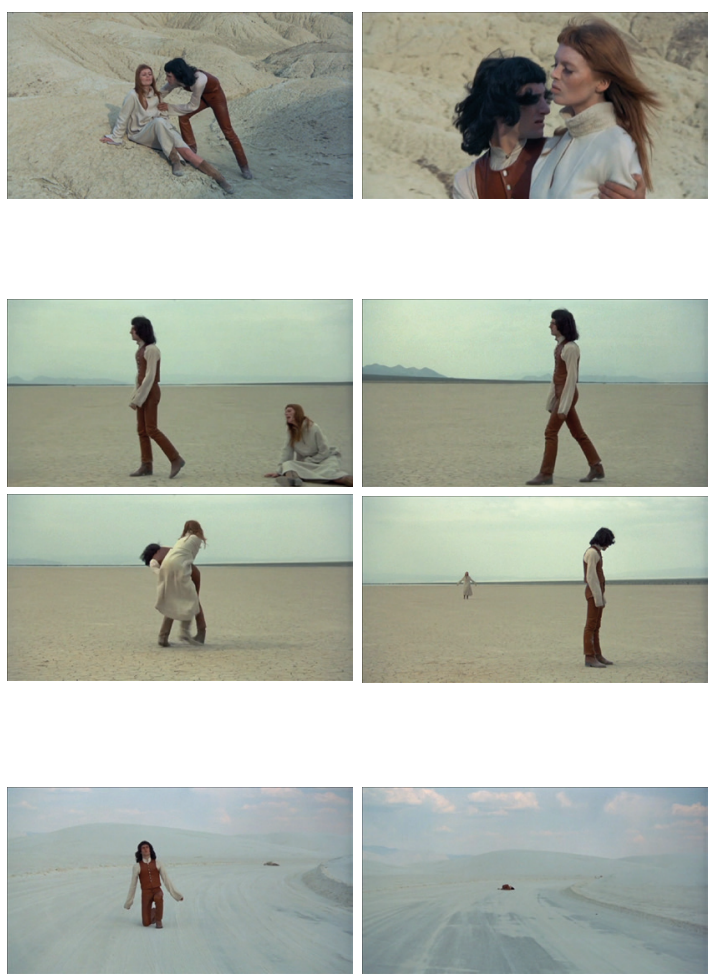

Fig. 4 La cicatrice intérieure (Philippe Garrel, 1972)

Se trataba de filmar con el otro para encontrar el oxígeno en el universo compartido del amor, para hallar la resistencia del deseo de salir de la espiral que los amantes trazaban sobre sí mismos. El travelling circular de La cicatrice intérieure se convertía en la metáfora más precisa. El filme arranca con Nico sentada a una roca del desierto, con los ojos cerrados, inmóvil. Garrel la levanta. "¿A dónde me llevas?", pregunta ella, mientras él sigue mirando atrás, temiendo que su gesto sea un rapto y 
buscando a su vez el lugar para no ser descubierto, para esconderse junto con ella, para huir y encontrar un refugio. El viaje de la circunferencia que vuelve al punto de partida dos veces (fig. 4B) manifiesta el deseo de escapar, de abandonar su proyecto, y a su vez la imposibilidad de realizarlo, o la necesidad de permanecer en el mismo sitio. En suma, asistimos al escenario de la cicatriz interior de los cuerpos: un corte inmenso en un desierto sin profundidad de campo, el movimiento es de observación atenta a este espacio a priori abierto al infinito, pero cerrado al mismo tiempo, ya que la circularidad delimita el espacio. Decía Garrel: "Este travelling es pues un plano secuencia en estado puro, una suerte de grado cero del plano secuencia" (1992: 64). En efecto, el plano secuencia transporta hacia un no-lugar, pero también hacia un no-tiempo. Porque el mismo cierre sobre la imagen, que borra cualquier otro espacio, en tanto que delimitación, genera un obstáculo para avanzar. Estamos frente a la matriz donde el cuerpo todavía tiene que nacer, frente al hueco oscuro de los orígenes, la Gola primigenia que Garrel, como apuntó Sergi Sánchez, presenta en forma de polvo blanco (Casas, 2007: 65-71).

Para poder retomar el movimiento era necesario hacer del lugar un no-lugar y del tiempo un no-tiempo. Pero para retomarlo de un modo distinto: como decíamos más arriba, desde una relación de cine con los cuerpos para hallar la solución o nuevos interrogantes a aquello que los cuerpos por sí mismos eran incapaces de pensar. La secuencia del travelling circular (fig. 4B) no casualmente se dispone entre dos secuencias que dotan la cámara de poder y autonomía frente a los cuerpos: pero si en el primer caso (fig. 4A) el movimiento de la cámara sigue Garrel en el gesto de recoger a Nico, en la secuencia posterior al travelling (fig. 4C) el movimiento ya no depende de la trayectoria de los cuerpos, y estos caen, separados, y dejan de agitarse, la cámara los abandona para seguir su trayecto.

\section{Conclusiones}

Al inicio de este artículo formulábamos una hipótesis: la Nouvelle Vague culminó con el cine moderno en la medida en que abordó la búsqueda y la reflexión de lo visible a partir de la relación con el Otro. En concreto, señalamos, llevó a cabo este proceso poniendo en crisis la relación narrativa para mantener o abogar por una nueva relación en términos de montaje y puesta en escena. Seguidamente, lanzábamos una pregunta: ¿cómo transformar la pérdida del Otro dentro del relato en la búsqueda de la naturaleza de la imagen? Y, si la Nouvelle Vague resuena en el cine contemporáneo, ¿cómo este proceso puede convertirse en un modelo a seguir por los cineastas?

En otro trabajo vimos cómo Truffaut inauguraba una tendencia en la historia del cine francés, concibiendo el actor como mediación del cineasta, y la búsqueda de la imagen como objeto de deseo (Vilaró, 2010: 19-40). En este estudio observábamos que la reinvención de los discursos posteriores que traviesan tres generaciones, de Jean Eustache a Leos Carax hasta Arnaud Desplechin, nacía del reto que planteaba el 
director de Les Quatre cents coups con la separación de la imaginación y la realidad. En este artículo vimos el caso de Resnais, de Godard y de Garrel, donde los elementos del relato se transforman en elementos figurativos cuando el cineasta decide abordar la narración, respectivamente, como si se tratara de una cuestión de tiempo, de espacio o propia de las actitudes de los cuerpos. La pluralidad de los discursos en las secuencias analizadas ratifica una de las primeras observaciones que hicimos: en la Nouvelle Vague existe una reivindicación de cada autor, y lo que une a los cineastas es por tanto la singularidad misma de la reivindicación y no la construcción de un universo estético determinado. Pero lo que exponen nuestros análisis y lo que confirma nuestra hipótesis es que la Nouvelle Vague hizo del filme el espacio para abordar una investigación sobre la relación.

"El cine representa una investigación de conjunto sobre el lazo, la relación. En el cine, todo está preso en una circulación" (Brenez, 1998: 12). Entre el objeto y el sujeto, la realidad, la representación, el cineasta, el espectador. Si la relación supone el sitio de la asociación, la interpelación, el contacto donde el lenguaje debe codificarse, para descubrir cómo un filme inventa una lógica figurativa, el análisis figural debe entenderse desde la permeabilidad de esta relación inmanente y ambigua no sólo con la realidad, en el sentido de Bazin, sino con los otros elementos que configuran la arquitectura de la imagen cinematográfica: la morfología de la imagen, las propiedades formales del plano, el tratamiento de los motivos. En este proceso, en el que, como dijimos, cada autor y cada film en particular crea un comportamiento de las imágenes, el film plantea problemas a resolver. Dice Jacques Aumont en relación al análisis fílmico: "el objeto del análisis no son las obras, son los problemas a los que -para que se constituyan- ellas han inventado soluciones", "son los problemas de imagen los que crean los filmes" (Aumont, 1996: 125, 150).

La Nouvelle Vague no culminó el cine moderno sólo por llevar la reflexión de lo visible al relato autorreferencial y a una nueva lógica del pensamiento de las imágenes, donde situábamos la búsqueda godardiana de lo visible o la imagen-tiempo según Deleuze. La Nouvelle Vague, abordando la relación como problema a resolver por los cineastas en el uso de las imágenes, situó la praxis y la teoría fílmica en el mismo plano e hizo del film el lugar de una exploración sobre la imagen a partir de lo figural en el sentido de François Lyotard, y rehusando la subordinación al texto.

Finalmente, consideramos necesarios unos apuntes sobre el cine francés contemporáneo. Si después de la Nouvelle Vague la separación de la pareja fue necesaria para vindicar la existencia de los cuerpos en la formación de las imágenes, las propuestas más actuales, para hablar de amor, requieren de la sublevación, de la aceptación del ser violado, de la aceptación de una muerte ya no poética, sino física. Baisemoi (Virginie Despentes, Coralie Trinh Thi, 2000), À ma søur ! (Catherine Breillat, 2001), Trouble Every Day (Claire Denis, 2001), Irréversible (Gaspar Noé, 2002), Tirésia (Bertrand Bonello, 2003), Le dernier des fous (Laurent Achard, 2006), L'Inconnu du lac (Alain Giraudie, 2013). En el film francés contemporáneo los cuerpos se desnudan y muestran la voluptuosidad como nueva tendencia: Dans ma peau (Marina de Van, 2002), Avant que j'oublie (Jacques Nolot, 2007), À l'aventure (Jean-Claude 
Brisseau, 2009), La vie d'Adèle: Chapitres 1 et 2 (Abdellatif Kechiche). Los cuerpos aparecen como la materia prima de las imágenes, y las historias -en clave feminista y homosexual en gran medida- dan hincapié a las comunidades que no fueron acogidas por el cine precedente, como reacción a su ausencia de representación, dirigiendo el relato a una intimidad donde ya no es la alteridad en sí lo que falta sino el sentimiento mismo de la alteridad. Los estudios sobre este nuevo cine francés (Vasse, 2008; Tassone, 2003; Samocki, 2002: 5-21) afirman una ruptura en relación con la historia precedente, $\mathrm{o}$ en todo caso hallan ecos de este cine contemporáneo en cineastas que hasta la fecha no destacaron por la construcción de sistemas estéticos, como Claude Chabrol o Maurice Pialat. A la espera de un trabajo más exhaustivo que aborde estas cuestiones, este artículo pone de manifiesto que no existe una ruptura con la Nouvelle Vague, sino que al contrario, ésta asentó las bases de la construcción de la alteridad y el viaje del deseo a partir de la separación.

\section{Referencias bibliográficas}

AAVV. (2006). Nouvelle Vague: una revolución tranquila. València: MuVIM.

ANDREW, Dudley (1978). Las principales teorías cinematográficas. Barcelona: Gustavo Gili.

(1983). André Bazin. París: Cahiers du Cinéma/L'Étoile.

(1987). Breathless: Jean-Luc Godard, director. New Brunswick: Rutgers University Press.

ASTRUC, Astruc (1992). Du stylo à la caméra et de la caméra au stylo. Paris: L'Archipel.

AUMONT, Jacques (1996). À quoi pensent les films? Paris : Séguier.

(1999) Amnésies. Fictions du cinéma d'après Jean-Luc Godard. Paris: POL.

BAECQUE, Antoine de (1998). La nouvelle vague. Portrait d'une jeunesse. Paris:

Flammarion.

BARTHES, Roland (1974). Le plaisir du texte. Paris : Seuil.

BAZIN, André (2008). ¿Qué es el cine? Madrid: Rialp.

BERGALA, Alain (2003). Nadie como Godard. Barcelona: Paidós.

BRENEZ, Nicole (1998). De la figure en général et du corps en particulier. L'invention figurative au cinéma. Paris: DeBoeck Université.

"'Filmar, como yo lo he hecho durante diez años, a una mujer a la que uno quiere es en sí algo bastante loco...'. Sistema simbólico y giro narrativo en la obra de Philippe Garrel". En: CASAS, Quim (coord.) (2007). Philippe Garrel: El cine revelado. Festival Internacional de Cine de San Sebastián. p. 73-79.

BUACHE, Freddy (1987). Le cinéma français des années 60. París: Hatier/Cinq Continents.

(1990). Le cinéma français des années 70. París: Hatier/Cinq Continents.

COLLET, Jean (1963). Jean-Luc Godard. París: Seghers.

(1972). Le Cinéma en question: Rozier, Chabrol, Rivette, Truffaut, Demy, Rohmer.

París: Lherminier. 
(1977). Le Cinéma de François Truffaut. París: Lherminier.

COURANT, Gérard (1983). Philippe Garrel. Entretiens, Paris, Studio 43.

CRISP, Colin (1972). François Truffaut. Nueva York/Londres, Praeger/Movie.

(1988). Eric Rohmer. Realist and Moralist. Bloomington: Indiana University Press.

(1993). Classic French Cinema (1930-1960). Bloomington: Indiana University Press.

DANEY, Serge (1993). L'exercice a été profitable, Monsieur. Paris: POL. (1998). Perseverancia. Reflexiones sobre el cine. Conversaciones con Serge Toubiana. Buenos Aires: El Amante.

DELEUZE, Gilles (2003). La imagen-movimiento. Estudios sobre cine 1. Barcelona: Paidós.

(2004). La imagen-tiempo. Estudios sobre cine 2. Barcelona: Paidós.

DOUCHET, Jean (1998). La Nouvelle Vague. París: Hazan.

FRONDON, Jean-Michel (1995). L'Âge moderne du cinéma français. De la Nouvelle Vague à nos tours. París: Flammarion.

GARREL, Philippe; LESCURE, Thomas (1992). Une caméra à la place du cœur. Provence Alpes Côte d'Azur: Admiranda/Institut de l'Image.

GAUTHIER, G. (dir) (2002). Flash-back sur la nouvelle vague. Condé-sur-Noireau: Corlet-Télérama-CinémAction.

GODARD, Jean-Luc (1998). Godard par Godard. Tome 1: 1950-1984. Paris: Cahiers du cinéma.

(2005) "El montaje, mi hermosa inquietud". En: BAECQUE, Antoine de. (comp.). Teoría y crítica del cine. Avatares de una cinefilia. Barcelona: Paidós. p. 33-35.

HEREDERO, Carlos; MONTERDE, José Enrique (eds.) (2002). En torno a la Nouvelle Vague. Rupturas y horizontes de la modernidad. València: Filmoteca de la Generalitat Valenciana.

KRACAUER, Sigfried (1989). Teoría del cine. La redención de la realidad fisica. Barcelona: Paidós.

LALANNE, Jean-Marc (2002). "Le cinéma français, modèle esthétique". En: Cahiers du cinéma, $\mathrm{n}^{\circ}$ 568, Paris: Cahiers du cinéma. p. 80-81.

LYOTARD, François (1979). Discurso, Figura. Barcelona: Gustavo Gil.

MAGNY, Joël (1986). Eric Rohmer. París: Rivages-Cinéma.

(1987). Claude Chabrol. París: Cahiers du Cinéma/L’Étoile.

y otros (1992). Marguerite Duras: el cine del desgarro. València: Ediciones de la Mirada.

(1993). Maurice Pialat. París: Cahiers du Cinéma.

MARIE, Michel (1997). La Nouvelle Vague. París: Nathan.

(comp.) (1999). El nuevo cine francés. València/Gijón: Filmoteca de la Generalitat/Festival de Cine de Gijón.

(2012). La Nouvelle Vague. Una escuela artística. Madrid: Alianza.

MEMBA, Javier (2003). La Nouvelle Vague. Madrid: T\&B.

OMS, Marcel (1988). Alain Resnais. Paris: Rivages. 
PONCE, Vicente (2006). La Nouvelle Vague: una revolución tranquila. València: MuVIM.

PRÉDAL, René (1984). Le Cinéma français contemporain. París: Cerf.

(1991). Le Cinéma français depuis 1945. París: Nathan.

(1996). 50 Ans de cinéma français. París: Nathan.

REVAULT D'ALLONES, Fabrice. "Séparations (Gare, elle...)". En PAÏNI, Dominique (dir.) (1988). Philippe Garrel. Ville de Pantin : Studio 43. p. 29.

RIAMBAU, Esteve (2002). El cine francés: 1958-1998. De la Nouvelle Vague al final de la escapada. Barcelona: Paidós.

y MONTERDE, José Enrique (1995). Nuevos cines (años 60). Historia general del cine. Vol. IX. Madrid: Cátedra.

ROUSSEAU, Jean-Jacques (1996). Els somiegs del passejant solitari. Barcelona: Proa.

SAMOCKI, Jean-Marie (2002). "La politique des chairs tristes". En: Trafic, no 44, Paris: POL. p. 5-21.

SÁNCHEZ, Sergi (2007). "No aquí. No ahora. De La Cicatrice intérieure y una cierta tendencia del cine contemporáneo". En CASAS, Quim (coord.). Philippe Garrel: El cine revelado. Festival Internacional de Cine de San Sebastián. p. 65-71.

TASSONE, Aldo (dir.) (2003). Que reste-t-il de la Nouvelle Vague? Paris: Stock.

TRUFFAUT, François (1999). El placer de la mirada. Barcelona: Paidós.

VASSE, David (2008). Le nouvel âge du cinéma français. Paris: Klincksieck.

VILARÓ, Arnau (2011). "L'errància de l'actor després d'Antoine Doinel: sobre una tendència melancòlica en el cinema francès contemporani”. En : Comunicació. Revista de Recerca i d'Anàlisi, n 28 (1). Barcelona: Institut d'Estudis Catalans. p. 19-40.

\section{Notas}

1 Nos referimos a los textos escritos por los mismos cineastas de la Nouvelle Vague. Célebres artículos como "Montage mon beau souci", de Godard, o "De l'abjection", de Rivette, los textos de Rohmer recogidos en Le cellulö̈d et le marbre o Le goût de la beauté; los de Truffaut en Les films de ma vie o Le plaisir des yeux, etc. También artículos sobre filmes de la Nouvelle Vague escritos por los mismos cineastas del grupo: Labarthe sobre Les Bonnes femmes o L'Année dernière à Marienbad; Rivette sobre Les Quatre cents coups o Godard sobre Les Cousins. Gran parte de estos textos fueron agrupados y reeditados por la misma editorial Cahiers du Cinéma entre 1998 y 2001 bajo siete antologías: Le goût de l'Amérique; Vive le cinéma français!; La Nouvelle Vague; La politique des auteurs. Les textes; La politique des auteurs. Les entretiens; Critique et Cinéphilie; Théories du cinéma.

2 Dominique Païni escribe re-garder, creando un juego de palabras con mirar (regarder) y guardar (garder). 